\title{
Article \\ Enhanced Power Extraction with Sediment Microbial Fuel Cells by Anode Alternation
}

\author{
Marzia Quaglio ${ }^{1,2, *}$, Daniyal Ahmed ${ }^{2}$, Giulia Massaglia ${ }^{1,2, * \mathbb{D}}$, Adriano Sacco ${ }^{2} \mathbb{D}$, Valentina Margaria ${ }^{2}$ and \\ Candido Fabrizio Pirri 1,2 (ID)
}

1 Department of Applied Science and Technology, Materials and Processes for Micro \& Nano Technologies, Politecnico di Torino, Corso Duca Degli Abruzzi 24, 10129 Torino, Italy; fabrizio.pirri@polito.it

2 Center for Sustainable Fututre Technologies@Polito, Istituto Italiano di Tecnologia, Via Livorno 60 10144 Torino, Italy; daniyal.ahmed@iit.it (D.A.); adriano.sacco@iit.it (A.S.); valentina.margaria@iit.it (V.M.)

* Correspondence: marzia.quaglio@polito.it (M.Q.); giulia.massaglia@polito.it (G.M.)

check for updates

Citation: Quaglio, M.; Ahmed, D.; Massaglia, G.; Sacco, A.; Margaria, V.; Pirri, C.F. Enhanced Power Extraction with Sediment Microbial Fuel Cells by Anode Alternation. Fuels 2021, 2, 168-178. https://doi.org/10.3390/ fuels2020010

Academic Editor: Martin Olazar

Received: 24 November 2020

Accepted: 28 April 2021

Published: 30 April 2021

Publisher's Note: MDPI stays neutral with regard to jurisdictional claims in published maps and institutional affiliations.

Copyright: (c) 2021 by the authors. Licensee MDPI, Basel, Switzerland. This article is an open access article distributed under the terms and conditions of the Creative Commons Attribution (CC BY) license (https:/ / creativecommons.org/licenses/by/ $4.0 /)$.

\begin{abstract}
Sediment microbial fuel cells (SMFCs) are energy harvesting devices where the anode is buried inside marine sediment, while the cathode stays in an aerobic environment on the surface of the water. To apply this SCMFC as a power source, it is crucial to have an efficient power management system, leading to development of an effective energy harvesting technique suitable for such biological devices. In this work, we demonstrate an effective method to improve power extraction with SMFCs based on anodes alternation. We have altered the setup of a traditional SMFC to include two anodes working with the same cathode. This setup is compared with a traditional setup (control) and a setup that undergoes intermittent energy harvesting, establishing the improvement of energy collection using the anodes alternation technique. Control SMFC produced an average power density of $6.3 \mathrm{~mW} / \mathrm{m}^{2}$ and SMFC operating intermittently produced $8.1 \mathrm{~mW} / \mathrm{m}^{2}$. On the other hand, SMFC operating using the anodes alternation technique produced an average power density of $23.5 \mathrm{~mW} / \mathrm{m}^{2}$. These results indicate the utility of the proposed anodes alternation method over both the control and intermittent energy harvesting techniques. The Anode Alternation can also be viewed as an advancement of the intermittent energy harvesting method.
\end{abstract}

Keywords: sediment microbial fuel cells; energy harvesting; Anode Alternation; intermittent energy harvesting

\section{Introduction}

Microbial fuel cells (MFCs) are bio-electrochemical systems that have been shown to produce electrical energy [1-5]. These devices are based on a special class of microorganisms known as the electro-active bacteria. Metabolic processes of electro-active bacteria enable them to convert chemical energy, stored in organic compounds, directly into electrical energy. Apart from energy harvesting, these devices also have a potential in the development of biological sensors and the treatment of waste water [6-11]. Different MFC types have been optimized over years, with specific architectural features that allow their optimal use in different applications [1-3]. Specifically introduced for use in natural sediments, sediment microbial fuel cells (SMFCs) have demonstrated in recent years to have great potential for wastewater treatment as well [12]. SMFCs are a type of MFCs in which the anode is suspended inside the sediment, creating anaerobic conditions and providing the fuel needed for the growth of bacteria, while the cathode floats on the surface in aerobic conditions [13].

Recently, a considerable amount of research has been performed on MFCs to understand them and improve the performance of MFCs in terms of anode materials [14-16], cathode catalysts [17,18], biofilm colonization [19-21], and with more specific works focusing on SMFCs [22-24]. 
The performance of MFCs, including SMFCs, depends upon several factors and one of them is the efficient electrical energy extraction. Traditionally, energy harvesting systems (acting as load for MFCs) have been used to extract energy from the MFCs in a continuous manner. This extracted energy is then stored in a battery $[25,26]$ or across a super-capacitor $[27,28]$. Furthermore, in some works, external resistances, acting as loads, are connected between the cathode and the anode of an MFC to demonstrate power production [29-33]. For the extraction of electrical energy, numerous electrical circuits have been proposed. Donovan et al. developed a custom power management system (PMS) for MFCs, based on capacitors and charge pumps, to intermittently power remote sensor [34]. On the other hand, Yang and co-workers used a transformer, instead of a charge pump, coupled with super capacitors to power a wireless sensor using MFCs [35]. Moreover, the concept of stack MFC has been exploited by Ledezma et al. to demonstrate a self-sustainable sensing and reporting system [36]. Furthermore, Kim et al. used an array of MFCs connected in parallel to charge an array of capacitors (connected in parallel as well). With the help of switches, these capacitors were then disconnected from the MFC and were connected in series with each other to provide a voltage of up to $2.5 \mathrm{~V}$ to the load, avoiding voltage reversal [37].

During the last years, new techniques and approaches of electrical energy extraction from MFCs have been proposed, especially exploiting the unique features of these devices. MFCs anode and cathode possess well-demonstrated capacitive features, which are responsible for the observed ability of MFCs to improve their power production if operated in pulsed mode instead of continuous operation [38-42]. Generally, MFCs are indeed subject to a constant load such as a resistance. This results in a constant extraction of power from the MFCs. One technique that has been explored extensively in the literature is known as the intermittent energy harvesting (IEH) [43-45]. IEH technique suggests the use of an external load intermittently. Indeed, in IEH technique, the MFC is connected and disconnected from an external load at different frequencies and at particular duty cycles (duty cycle is the ratio of time for which a particular anode is used to harvest energy to the time it rests to accumulate charge, within that cycle). The duration in which the MFC is disconnected from the load allows accumulation of charges on the electrodes of an MFC. Afterwards, when the MFC is connected to the load, at the start of next cycle, a burst of charge is available for the load to consume. It is undoubtedly demonstrated in the literature that the use of IEH technique with an intermittent load application can significantly improve the overall performance of MFCs [46-48]. Two main factors have been proposed in the literature to work concurrently to cause the energy harvesting improvement for MFCs operated intermittently $[49,50]$. The first one is based on the capacitive behavior of biofilms, in which c-type cytochromes can accumulate charges during intermittent mode [51]. The second concurrent factor is an improvement in mass transport. Intermittent strategies help delivering more electron donors to the bottom of biofilms, thus improving bacterial activity. Based on these observations, intermittent polarization methods have been proposed to promote the formation of highly active biofilms [52], providing final evidence that electroactive biofilms significantly benefit from working in intermittent mode.

In this work, we explore a novel electrical technique to extract energy from SMFCs that we called Anode Alternation. We propose to reform the setup of a SMFC to include two anodes, rather than one, working alternatively with the same cathode. Consequently, such a setup would enable us to alternate the use of the anodes, resulting in a more efficient SMFC, as opposed to a classic single anode SMFC. The starting point of Anode Alternation technique is the "intermittence" concept of IEH, but it improves power extraction with respect to IEH by enabling a single MFC to be in an "always-on mode," thanks to the presence of two anodes. This is opposed to what occurs with IEH in which an MFC is alternatively in "on mode" or "off-mode," the latter corresponding to charge accumulation on the electrodes. Furthermore, using the Anode Alternation technique, only a single MFC needs to be setup, theoretically, to do the same amount of work as two MFCs based on IEH. This reduces the overall cost of the device related to the setup and the number of cathodes 
limiting the catalyst required. Additionally, it is more convenient and space effective to setup a single MFC with two anodes rather than two separate MFCs.

\section{Materials and Methods}

\subsection{Biofilm Development}

For the colonization and development of biofilm, pieces of carbon felt (Soft felt SIGRATHERM GFA5, SGL Carbon, Bonn, Germany) were placed underwater in a sea in the north of Italy. Carbon felt was buried approximately $3 \mathrm{~m}$ below sea water in the sediment and was left there for 1 month [53]. In order to improve biofilm formation, the felt was initially soaked in PBS containing $2.5 \mathrm{~g} / \mathrm{L}$ of sodium acetate. After the colonization phase, these pieces of carbon felt, on which the biofilm had formed, were used to setup the SMFCs.

\subsection{Experimental Setup}

The SMFCs were setup in plastic containers (with a volume of $5 \mathrm{~L}$ ). Colonized carbon felt from the biofilm development phase was used as anode material. In each container, two $3 \times 3 \mathrm{~cm}^{2}$ large pieces of the colonized carbon felt were placed on opposite corners. For different experiments, the two anodes were either electrically shorted via an external switch (to act as a single anode) or were used as two different anodes working with the same cathode. The distance between both the carbon felt pieces, acting as anode(s), inside the plastic container, was close to $15 \mathrm{~cm}$. Previous setups of this experiment showed that the anodes were affected by electrical interference from each other if the distance between the anodes was too short. Therefore, to avoid any sizeable cross-talk between the anodes, this distance was chosen.

For the cathodes, carbon paper (by Fuel cell earth, Woburn, USA) coated with a catalyst layer was used. This catalyst layer is based on platinum $\left(0.5 \mathrm{mg} \mathrm{cm}^{-2} \mathrm{of} \mathrm{Pt} / \mathrm{C}\right.$ obtained by Sigma Aldrich) and $5 \mathrm{wt} \%$ of Nafion (Sigma Aldrich, St. Louis, Missouri, USA) [11]. One cathode, with an area of $6 \times 3 \mathrm{~cm}^{2}$, was used for each SMFC, ensuring an optimal 1 to 1 ratio between the area of the cathode and the maximum anodic areas, corresponding to the sum of the two anodes' areas [54]. Cathodes were placed near the water's surface for efficient aeration, leading thus to provide an optimized direct oxygen reduction reaction (ORR).

In the case of anode, external electrical connections were made using a titanium wire sown onto the carbon felt. On the other hand, for the cathodes, titanium wire was attached to the carbon paper using a carbon-based conductive cement. The anodes were then covered with sea sediment, containing pebbles to favor diffusion of species in the sediment layer. Seawater was used to fill the plastic container to recreate a marine environment. No additional seawater and/or nutrients were added throughout the length of the experiments ( $\sim 4$ months). The container was covered with a drilled lid in order to avoid rapid evaporation of the seawater while ensuring water aeration. A sketch of the experimental setup is depicted in Figure 1a). The experiment was setup as duplicate using identical plastic containers. 
a)

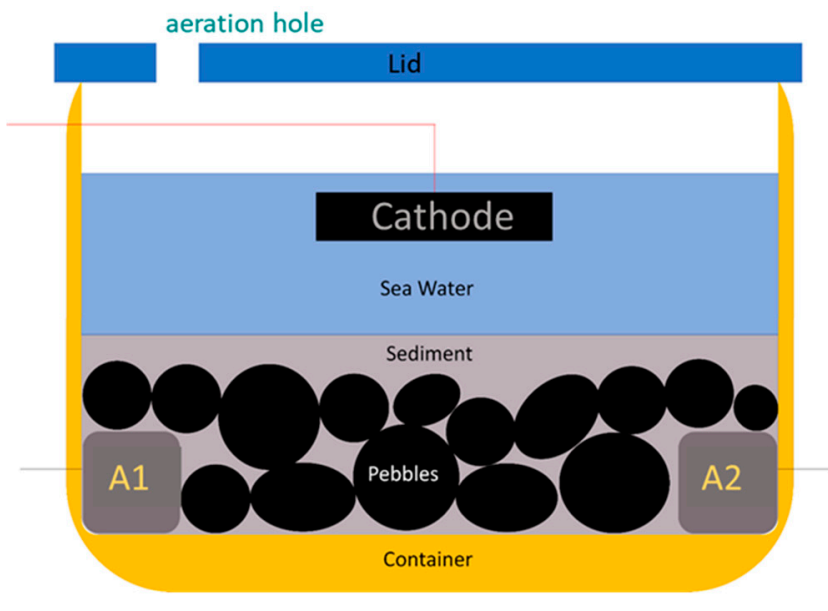

b)
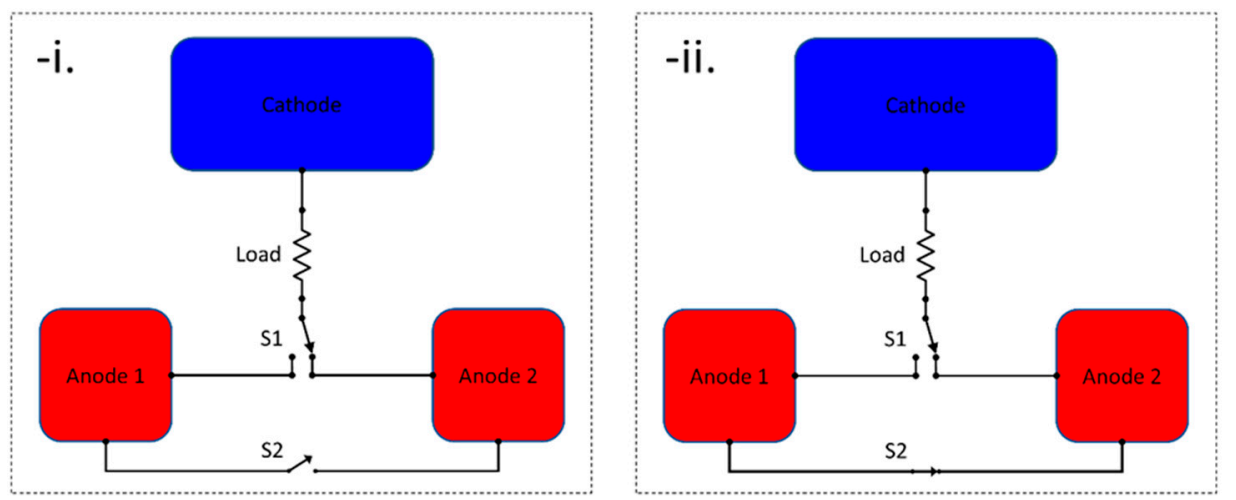

Figure 1. In (a), a sketch of the experimental setup is presented: A1 and A2 represent the anodes; in (b), the electrical connection of the sediment microbial fuel cells (SMFCs) in two different configurations is shown: in -i, SMFC operated with two different anodes and in configuration -ii, SCMFC operated with the two anodes electrically shorted together.

Once the setup was complete, the SMFCs were left to stabilize at room temperature, i.e., $(21 \pm 2)^{\circ} \mathrm{C}$, under an external load of $6.8 \mathrm{k} \Omega$ for a period of 2 months.

\subsection{Characterization}

During all the experiments, voltage of the SMFCs was recorded using the Agilent 34972A data acquisition system. VSP potentiostat (BioLogic, Seyssinet-Pariset, France) was used to perform chronoamperometry on the cells to obtain the power produced by the system at a specific voltage during a fixed period of time. This voltage was chosen as the half of open circuit potential (OCP) to optimize the power extracted [55].

In this work, a novel approach for power extraction was tested using our SMFC setup. Power was extracted from the two nominally identical SMFCs working in different anode configurations as reported in Figure 1b). Different operation modes were possible by properly selecting the position of switches S1 and S2. SMFCs with configuration -i. operated with two separate anodes for testing Anode Alternation and IEH techniques (Figure 1b(-i)), while SMFCs with configuration -ii. operated with the two anodes electrically shorted together to act as a single anode continuously working for the whole period of the experiment (Figure $1 \mathrm{~b}(-\mathrm{ii})$ ). The power extracted was measured using the method previously mentioned (i.e., chronoamperometry). Chronoamperometry was performed for $10 \mathrm{~h}$. For the application of Anode Alternation technique, the two anodes were kept isolated from each other by opening the switch S2 (Figure $1 \mathrm{~b}(-\mathrm{i})$ ). For the purpose of explanation, let us consider the two anodes as anode1 and anode2.

Anode2 was used to extract energy for $30 \mathrm{~min}$, while anode1 was kept in an open circuit condition with respect to the cathode (and hence was resting). This configuration 
was switched using the switch S1 at the end of each 30 min cycle. Therefore, in the second cycle, anode2, which was used to extract energy in the first cycle rested, while anode1, which rested in the first cycle, was used to extract energy. This alternating behavior went on for $10 \mathrm{~h}$ (for each experimental run), and hence, there were a total of 20 cycles. For the implementation of the IEH technique, the anodes were again kept isolated from each other by keeping switch S2 open (Figure 1b(-i)).

Chronoamperometry was performed intermittently with a cycle length of $1 \mathrm{~h}$ and a duty cycle of $50 \%$. These parameters were chosen in order to match the operational time of a particular anode in between the two techniques Anode Alternation and IEH.

Energy was extracted for a total period of $10 \mathrm{~h}$. Lastly, to test the continuous energy harvesting technique, anodes of the cells were shorted together by closing switch S2 (Figure 1b(-ii)) hence, the two anodes acted as a single anode. Consequently, in the case of continuous energy harvesting technique, position of the switch S1 is irrelevant. Using all three techniques, we were able to gather data for a true comparison of the three in terms of average power density.

\section{Results and Discussion}

In this experiment, we analyzed a switching anode configuration to extract energy from the SMFCs. We compared this configuration with the already existing techniques such as IEH and continuous energy harvesting. After the stabilization period, chronoamperometry was performed on all the cells in the three different configurations to obtain the power density produced by each mode of operation. For power densities evaluation in each operation mode, the area of the anode actually in use during that mode was considered, meaning that for SMFCs working in continuous or IEH modes, the anode area was considered equal to the sum of the areas of the two anodes (i.e., $18 \mathrm{~cm}^{2}$ ), while during the ADAM mode, the area of one anode was considered (i.e., $9 \mathrm{~cm}^{2}$ ). Figure 2 shows these results. Over the course of $10 \mathrm{~h}$, SMFC operating under the Anode Alternation technique was able to produce an average power density of $23.5 \mathrm{~mW} / \mathrm{m}^{2}$. This value is an average of power density produced by each anode in its respective cycle. On the other hand, SMFC operating under the continuous energy harvesting approach was able to produce an average power density of $6.3 \mathrm{~mW} / \mathrm{m}^{2}$. As a first, we have demonstrated that SMFCs working in the Anode Alternation configuration were able to produce an average power density more than five times higher than that produced by SMFCs operating under the continuous mode. Moreover, it can be seen from Figure 3 that each anode of the SMFC (working in the Anode Alternation configuration) followed a unique pattern, during each cycle, which shows repeatability in the specific anode's behavior. Furthermore, this pattern is different within the two anodes. This can be associated to the fact that the two anodes have biofilms that function in a slightly different manner. One more result can therefore be associated to the ability of the Anode Alternation technique to preserve the specific behavior of the native anode, making possible to envisage future applications of energy harvesting combined to other functions (sensing, remediation, etc.). 


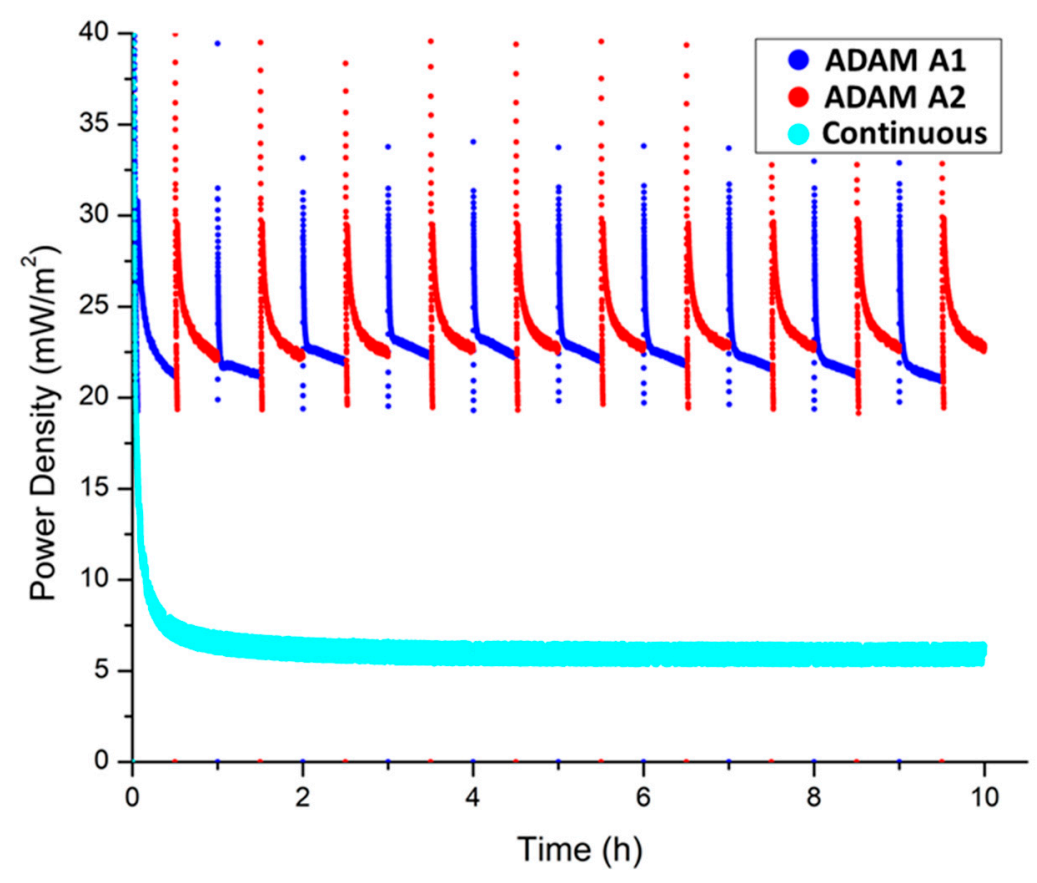

Figure 2. Power densities obtained from SMFCs operating under Anode Alternation and continuous energy harvesting configurations. The results from SMFC operating in Anode Alternation mode have been color labeled for the two different anodes working alternatively.

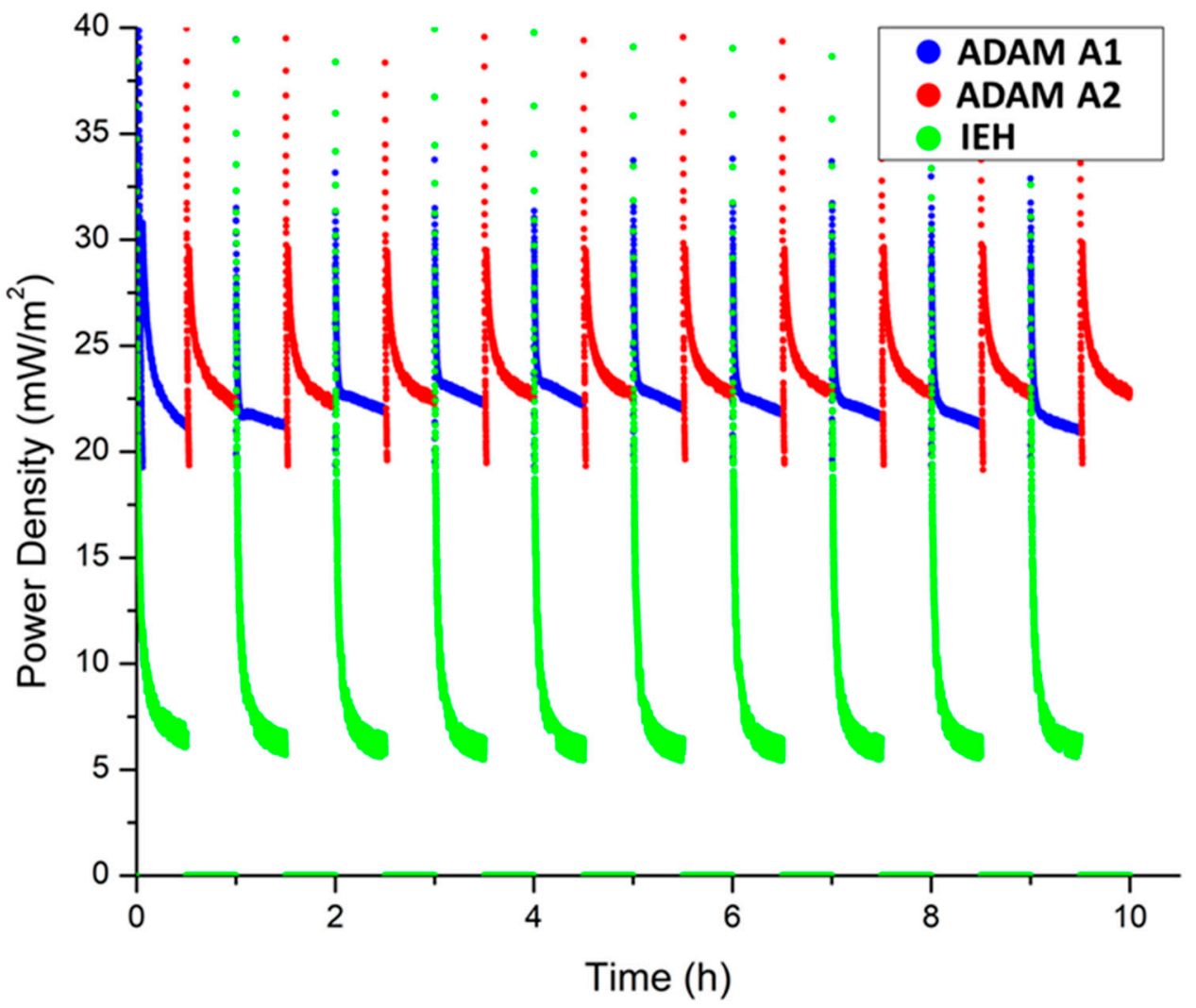

Figure 3. Power densities obtained from SMFCs operating under Anode Alternation and Intermittent (i.e., intermittent energy harvesting (IEH)) configurations. The results from SMFC operating in Anode Alternation configuration have been color labeled for the two different anodes working alternatively. 
After this initial comparison of the Anode Alternation technique with the more widely used continuous energy harvesting technique, we also performed experiments using the same SMFCs working in the IEH configuration. The results from these experiments are shown in Figure 3, where SMFCs operating under the IEH mode are compared to SMFCs operating under Anode Alternation mode. SMFCs operating intermittently were able to produce an average power density of $8.1 \mathrm{~mW} / \mathrm{m}^{2}$, which is higher than the power extracted by devices operating continuously (see Figure 3 ) but lower than the power produced by SMFCs working in the Anode Alternation configuration

The results obtained from the experiments indicate that the SMFCs working using the Anode Alternation technique were able to outperform SMFCs working in both the continuous energy harvesting mode and IEH mode thus confirming the superiority of the Anode Alternation technique in terms of power extraction.

Another important aspect of Anode Alternation configuration is the recovery time of an anode just after it has been through an energy-extraction cycle. In Figure 4, the OCPs of both anodes of the SMFC, using the Anode Alternation technique, are shown. In this experimental run, anode1 (blue dots) is used to extract energy for the first $30 \mathrm{~min}$, while anode2 (red dots) is kept as an open circuit.

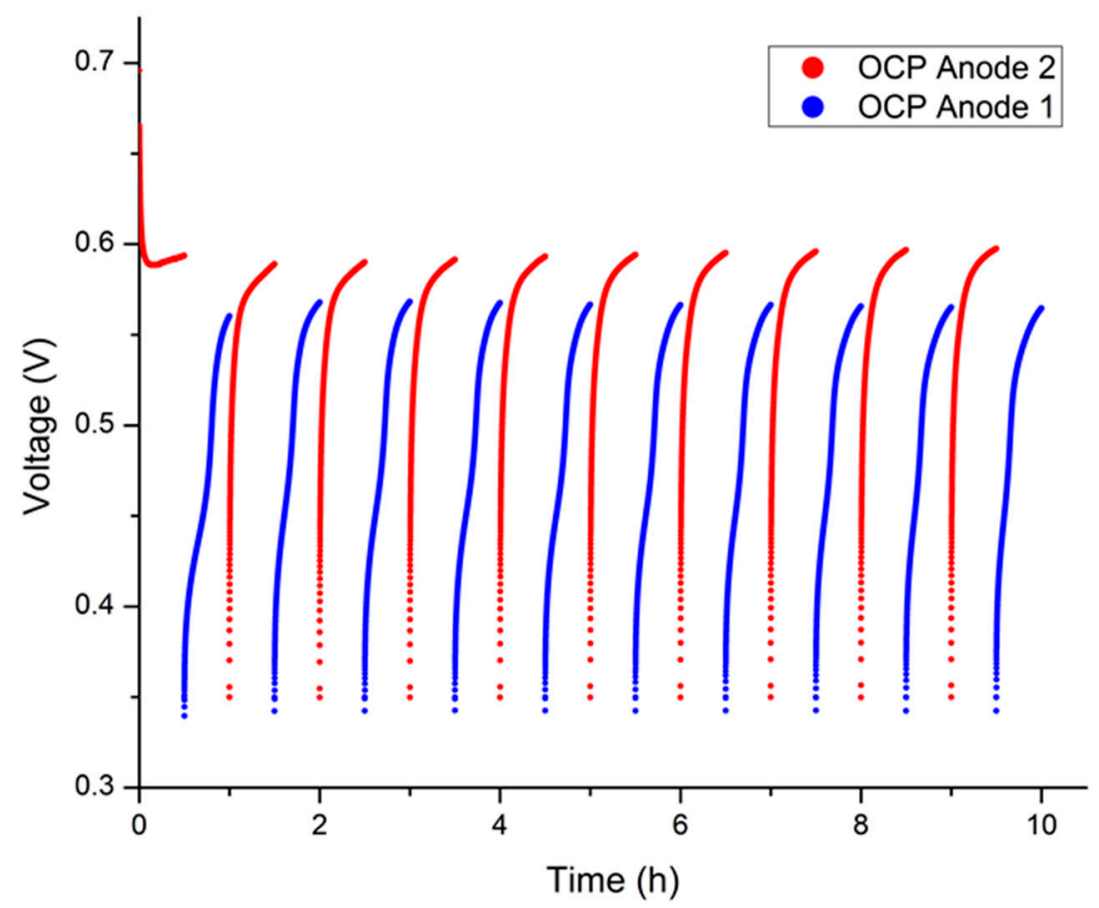

Figure 4. Open circuit potential (OCP) of the respective anode, over the total period of one experimental run. This experimental run is the same for which the power densities are shown in Figure 3.

A sharp decrease of $\sim 100 \mathrm{mV}$ in the OCP of anode 2 can be seen in the very start of the experiment. This decrease in the OCP of anode1 with respect to the cathode can be attributed to the (slight) electrical coupling of the two anodes within the cell through the medium (sea water). Furthermore, the image shows how each anode has a unique settling time and pattern when returning to the open circuit state. Moreover, this repeatability of the open circuit behavior of SMFC's anodes is in line with what was seen before in the power density plots of Figures 3 and 4. In fact, considering the individual performances of the two anodes, anode1 produced an average power density of $22.8 \mathrm{~mW} / \mathrm{m}^{2}$, while anode 2 produced an average power density of $24.1 \mathrm{~mW} / \mathrm{m}^{2}$. This better performance of anode2 can be associated with a higher recovery voltage reached in the open circuit condition shown in Figure 4. The capability for each anode to reach the same open circuit voltage value allows confirming that this proposed method do not affect the durability of anode 
electrode and consequently do not induce the degradation of electrode. This consideration is also confirmed by analyzing power densities' trends, obtained from SCMFCs operating in Anode Alternation configuration, that followed a unique pattern during each cycle reaching the same maximum power density value.

All obtained results clearly indicate the utility of this innovative approach to extract energy from SMFCs. Dual anode SMFC system operating in an alternating anode manner performs much better than the dual anode SMFC system in which both the anodes are used continuously to extract energy. Furthermore, it also shows improvement over the IEH technique using the same duty cycle. Indeed, the SCMFs, using the Anode Alternation technique, were able to produce an average power density of 3.7 times higher than the ones reached by SMFCs working in the continuous energy harvesting system. Similarly, Anode Alternation-based SMFCs showed an improvement in average power density extracted of about $580 \%$ when compared to SMFCs working in the IEH mode. Such behavior can be attributed to the fact that (S)MFCs' have a capacitive nature, which results in a spontaneous ability of the devices to perform better exploiting their spontaneous ability to switch to a "charge accumulation" phase just after an "energy extraction" one [56,57]. When comparing with the IEH technique, Anode Alternation technique can be viewed as an advancement of IEH technique by effectively doubling the energy extraction time within an operational period. To achieve a similar energy extraction time using the IEH technique, two SMFCs (with two cathodes) would be required. On the other hand, Anode Alternation technique exploits the use of two anodes working with the same cathode alternatively, thus reducing the overall cost and effort required in setting up a similar system using the IEH technique. Furthermore, these "cycles" of alternation can vary in time and duty cycle for different SMFCs and MFCs, thus further improving their performance. Moreover, during recovery phase, the anode can restore its potential difference with respect to the cathode, therefore, giving a surge in current when it goes back to energy extraction phase. This can be seen as the peaks in power density at the start of each cycle.

The voltage recovery pattern (in the open circuit condition i.e., the resting phase) of each anode during the 10-h experiment is also quite interesting. The results confirmed that all anodes follow a specific pattern each time they shift to the open circuit condition. This pattern is almost identical for each anode. Therefore, it is possible to assume that an alternating configuration is not perturbating the anode's response to changes in external load conditions. The response time/recovery pattern of an anode, which depends upon its biofilm development and internal impedances, remains the same. Further works will investigate the optimal "duty-cycle" of an anode in an Anode Alternation-based system. Moreover, the use of several anodes in one cell will also be explored to further optimize recovery period and consequently the energy extraction. Finally, it is important to highlight that application of Anode Alternation technique is not limited to SMFCs but can be extended to other types of MFCs.

\section{Conclusions}

A novel electrical approach to extract power more efficiently from SMFCs, Anode Alternation, was analyzed in this work. Considerable differences in the amount of power extracted from SMFC working in a traditional setup and the approach we propose of an alternating anode system are reported. Furthermore, results obtained from the Anode Alternation technique were also compared to the intermittent energy harvesting approach, with the Anode Alternation technique having a considerable advantage over intermittent energy harvesting approach. Moreover, the approach is applied to SMFCs without any addition of nutrients throughout the course of our experiments except those that were already present in the sea-water, which was initially added to the containers. Hence, an improvement in the performance of a sustainable energy harvesting device has been achieved by introducing a more dynamic method of energy extraction. 
Author Contributions: The following statement is proposed in order to specify the contribution of each co-author. M.Q. and G.M. conceived the work. G.M. and D.A. worked on the MFCs experiment and setup. A.S. carried on the electrochemical characterization. V.M. worked on the bacteria proliferation and electrodes' colonization. M.Q. worked on the design and preparation of MFCs. C.F.P. and M.Q. organized the research activity. All authors contributed to the final manuscript. All authors have read and agreed to the published version of the manuscript.

Funding: This research received no external funding.

Institutional Review Board Statement: Not applicable.

Informed Consent Statement: Not applicable.

Conflicts of Interest: The authors declare no conflict of interest.

\section{References}

1. Slate, A.J.; Whitehead, K.A.; Brownson, D.A.; Banks, C.E. Microbial fuel cells: An overview of current technology. Renew. Sustain. Energy Rev. 2019, 101, 60-81. [CrossRef]

2. Gajda, I.; Greenman, J.; Ieropoulos, I.A. Recent advancements in real-world microbial fuel cell applications. Curr. Opin. Electrochem. 2018, 11, 78-83. [CrossRef]

3. Santoro, C.; Arbizzani, C.; Erable, B.; Ieropoulos, I. Microbial fuel cells: From fundamentals to applications. A review. J. Power Sources 2017, 356, 225-244. [CrossRef]

4. Harnisch, F.; Schröder, U. From MFC to MXC: Chemical and biological cathodes and their potential for microbial bioelectrochemical systems. Chem. Soc. Rev. 2010, 39, 4433-4448. [CrossRef] [PubMed]

5. Dewan, A.; Donovan, C.; Heo, D.; Beyenal, H. Evaluating the performance of microbial fuel cells powering electronic de-vices. J. Power Sources 2010, 195, 90-96. [CrossRef]

6. Ezziat, L.; ElAbed, A.; Ibnsouda, S.; El Abed, S.; ElAbed, A. Challenges of Microbial Fuel Cell Architecture on Heavy Metal Recovery and Removal from Wastewater. Front. Energy Res. 2019, 7, 00001. [CrossRef]

7. Agostino, V.; Massaglia, G.; Gerosa, M.; Sacco, A.; Saracco, G.; Margaria, V.; Quaglio, M. Environmental electroactive consortia as reusable biosensing element for freshwater toxicity monitoring. New Biotechnol. 2020, 55, 36-45. [CrossRef]

8. Hu, J.; Zhang, Q.; Lee, D.-J.; Ngo, H.H. Feasible use of microbial fuel cells for pollution treatment. Renew. Energy 2018, 129, 824-829. [CrossRef]

9. Margaria, V.; Tommasi, T.; Pentassuglia, S.; Agostino, V.; Sacco, A.; Armato, C.; Chiodoni, A.; Schilirò, T.; Quaglio, M. Effects of $\mathrm{pH}$ variations on anodic marine consortia in a dual chamber microbial fuel cell. Int. J. Hydrogen Energy 2017, 42, 1820-1829. [CrossRef]

10. Chouler, J.; Di Lorenzo, M. Water Quality Monitoring in Developing Countries; Can Microbial Fuel Cells be the Answer? Biosensors 2015, 5, 450-470. [CrossRef]

11. Di Lorenzo, M.; Thomson, A.R.; Schneider, K.; Cameron, P.J.; Ieropoulos, I. A small-scale air-cathode microbial fuel cell for on-line monitoring of water quality. Biosens. Bioelectron. 2014, 62, 182-188. [CrossRef] [PubMed]

12. Xu, B.; Ge, Z.; He, Z. Sediment microbial fuel cells for wastewater treatment: Challenges and opportunities. Environ. Sci. Water Res. Technol. 2015, 1, 279-284. [CrossRef]

13. Zabihallahpoor, A.; Rahimnejad, M.; Talebnia, F. Sediment microbial fuel cells as a new source of renewable and sustainable energy: Present status and future prospects. RSC Adv. 2015, 5, 94171-94183. [CrossRef]

14. Salar-Garcia, M.; Montilla, F.; Quijada, C.; Morallon, E.; Ieropoulos, I. Improving the power performance of urine-fed microbial fuel cells using PEDOT-PSS modified anodes. Appl. Energy 2020, 278, 115528. [CrossRef]

15. Massaglia, G.; Margaria, V.; Fiorentin, M.R.; Pasha, K.; Sacco, A.; Castellino, M.; Chiodoni, A.; Bianco, S.; Pirri, F.C.; Quaglio, M. Nonwoven mats of $\mathrm{N}$-doped carbon nanofibers as high-performing anodes in microbial fuel cells. Mater. Today Energy 2020, 16, 100385. [CrossRef]

16. Hung, Y.-H.; Liu, T.-Y.; Chen, H.-Y. Renewable Coffee Waste-Derived Porous Carbons as Anode Materials for High-Performance Sustainable Microbial Fuel Cells. ACS Sustain. Chem. Eng. 2019, 7, 16991-16999. [CrossRef]

17. Santoro, C.; Serov, A.; Artyushkova, K.; Atanassov, P. Platinum group metal-free oxygen reduction electrocatalysts used in neutral electrolytes for bioelectrochemical reactor applications. Curr. Opin. Electrochem. 2020, 23, 106-113. [CrossRef]

18. Chiodoni, A.; Salvador, G.; Massaglia, G.; Delmondo, L.; Muñoz-Tabares, J.; Sacco, A.; Garino, N.; Castellino, M.; Margaria, V.; Ahmed, D.; et al. MnxOy- based cathodes for oxygen reduction reaction catalysis in microbial fuel cells. Int. J. Hydrogen Energy 2019, 44, 4432-4441. [CrossRef]

19. Agostino, V.; Ahmed, D.; Sacco, A.; Margaria, V.; Armato, C.; Quaglio, M. Electrochemical analysis of microbial fuel cells based on enriched biofilm communities from freshwater sediment. Electrochim. Acta 2017, 237, 133-143. [CrossRef]

20. Massaglia, G.; Fiorello, I.; Sacco, A.; Margaria, V.; Pirri, C.F.; Quaglio, M. Biohybrid Cathode in Single Chamber Microbial Fuel Cell. Nanomaterials 2018, 9, 36. [CrossRef] [PubMed] 
21. Armato, C.C.; Ahmed, D.; Agostino, V.; Traversi, D.; Degan, R.; Tommasi, T.; Margaria, V.; Sacco, A.; Gilli, G.; Quaglio, M.; et al. Anodic microbial community analysis of microbial fuel cells based on enriched inoculum from freshwater sediment. Bioprocess. Biosyst. Eng. 2019, 42, 697-709. [CrossRef] [PubMed]

22. Hong, S.W.; Chang, I.S.; Choi, Y.S.; Chung, T.H. Experimental evaluation of influential factors for electricity harvesting from sediment using microbial fuel cell. Bioresour. Technol. 2009, 100, 3029-3035. [CrossRef]

23. Song, T.-S.; Jiang, H.-L. Effects of sediment pretreatment on the performance of sediment microbial fuel cells. Bioresour. Technol. 2011, 102, 10465-10470. [CrossRef]

24. Ewing, T.; Ha, P.T.; Beyenal, H. Evaluation of long-term performance of sediment microbial fuel cells and the role of natural resources. Appl. Energy 2017, 192, 490-497. [CrossRef]

25. Cheng, S.; Liu, H.; Logan, B.E. Increased performance of single-chamber microbial fuel cells using an improved cathode structure. Electrochem. Commun. 2006, 8, 489-494. [CrossRef]

26. Ieropoulos, I.A.; Ledezma, P.; Stinchcombe, A.; Papaharalabos, G.; Melhuish, C.; Greenman, J. Waste to real energy: The first MFC powered mobile phone. Phys. Chem. Chem. Phys. 2013, 15, 15312-15316. [CrossRef] [PubMed]

27. Yang, Y.; Lu, Z.; Lin, X.; Xia, C.; Sun, G.; Lian, Y.; Xu, M. Enhancing the bioremediation by harvesting electricity from the heavily contaminated sediments. Bioresour. Technol. 2015, 179, 615-618. [CrossRef]

28. Huang, R.; Zheng, Q.; Zhao, F.; Mo, B. Power Management System for Microbial Fuel Cells. Available online: https://dl.acm. org/doi/abs/10.5555/2550268.2550356 (accessed on 30 April 2021).

29. Walter, X.A.; Stinchcombe, A.; Greenman, J.; Ieropoulos, I. Urine transduction to usable energy: A modular MFC approach for smartphone and remote system charging. Appl. Energy 2017, 192, 575-581. [CrossRef]

30. Meehan, A.; Gao, H.; Lewandowski, Z. Energy Harvesting With Microbial Fuel Cell and Power Management System. IEEE Trans. Power Electron. 2010, 26, 176-181. [CrossRef]

31. Rezaei, F.; Richard, T.L.; Brennan, R.A.; Logan, B.E. Substrate-Enhanced Microbial Fuel Cells for Improved Remote Power Generation from Sediment-Based Systems. Environ. Sci. Technol. 2007, 41, 4053-4058. [CrossRef] [PubMed]

32. Pinto, R.; Srinivasan, B.; Guiot, S.; Tartakovsky, B. The effect of real-time external resistance optimization on microbial fuel cell performance. Water Res. 2011, 45, 1571-1578. [CrossRef]

33. Jadhav, G.; Ghangrekar, M. Performance of microbial fuel cell subjected to variation in $\mathrm{pH}$, temperature, external load and substrate concentration. Bioresour. Technol. 2009, 100, 717-723. [CrossRef] [PubMed]

34. Donovan, C.; Dewan, A.; Peng, H.; Heo, D.; Beyenal, H. Power management system for a $2.5 \mathrm{~W}$ remote sensor powered by a sediment microbial fuel cell. J. Power Sources 2011, 196, 1171-1177. [CrossRef]

35. Yang, F.; Zhang, D.; Shimotori, T.; Wang, K.-C.; Huang, Y. Study of transformer-based power management system and its performance optimization for microbial fuel cells. J. Power Sources 2012, 205, 86-92. [CrossRef]

36. Ledezma, P.; Stinchcombe, A.; Greenman, J.; Ieropoulos, I. The first self-sustainable microbial fuel cell stack. Phys. Chem. Chem. Phys. 2013, 15, 2278-2281. [CrossRef] [PubMed]

37. Kim, Y.; Hatzell, M.C.; Hutchinson, A.J.; Logan, B.E. Capturing power at higher voltages from arrays of microbial fuel cells without voltage reversal. Energy Environ. Sci. 2011, 4, 4662-4667. [CrossRef]

38. Deeke, A.; Sleutels, T.H.J.A.; Hamelers, H.V.M.; Buisman, C.J.N. Capacitive Bioanodes Enable Renewable Energy Storage in Microbial Fuel Cells. Environ. Sci. Technol. 2012, 46, 3554-3560. [CrossRef]

39. Ieropoulos, I.; Greenman, J.; Melhuish, C.; Hart, J. Energy accumulation and improved performance in microbial fuel cells. J. Power Sources 2005, 145, 253-256. [CrossRef]

40. Houghton, J.; Santoro, C.; Soavi, F.; Serov, A.; Ieropoulos, I.; Arbizzani, C.; Atanassov, P. Supercapacitive microbial fuel cell: Characterization and analysis for improved charge storage/delivery performance. Bioresour. Technol. 2016, 218, 552-560. [CrossRef]

41. Poli, F.; Seri, J.; Santoro, C.; Soavi, F. Boosting Microbial Fuel Cell Performance by Combining with an External Supercapacitor: An Electrochemical Study. ChemElectroChem 2020, 7, 893-903. [CrossRef]

42. Soavi, F.; Santoro, C. Supercapacitive operational mode in microbial fuel cell. Curr. Opin. Electrochem. 2020, 22, 1-8. [CrossRef]

43. Dewan, A.; Beyenal, H.; Lewandowski, Z. Intermittent Energy Harvesting Improves the Performance of Microbial Fuel Cells. Environ. Sci. Technol. 2009, 43, 4600-4605. [CrossRef]

44. Wang, Y.; Chen, Y.; Wen, Q. Microbial fuel cells: Enhancement with a polyaniline/carbon felt capacitive bioanode and reduction of $\mathrm{Cr}(\mathrm{VI})$ using the intermittent operation. Environ. Chem. Lett. 2017, 16, 319-326. [CrossRef]

45. Walter, X.; Greenman, J.; Ieropoulos, I. Intermittent load implementation in microbial fuel cells improves power performance. Bioresour. Technol. 2014, 172, 365-372. [CrossRef]

46. Fradler, K.R.; Kim, J.R.; Boghani, H.C.; Dinsdale, R.M.; Guwy, A.J.; Premier, G.C. The effect of internal capacitance on power quality and energy efficiency in a tubular microbial fuel cell. Process. Biochem. 2014, 49, 973-980. [CrossRef]

47. Liang, P.; Yuan, L.; Wu, W.; Yang, X.; Huang, X. Enhanced performance of bio-cathode microbial fuel cells with the applying of transient-state operation modes. Bioresour. Technol. 2013, 147, 228-233. [CrossRef]

48. Grondin, F.; Perrier, M.; Tartakovsky, B. Microbial fuel cell operation with intermittent connection of the electrical load. J. Power Sources 2012, 208, 18-23. [CrossRef]

49. Guo, F.; Babauta, J.T.; Beyenal, H. Impact of intermittent polarization on electrode-respiring Geobacter sulfurreducens biofilms. J. Power Sources 2018, 406, 96-101. [CrossRef] 
50. Sun, D.; Cheng, S.; Zhang, F.; Logan, B.E. Current density reversibly alters metabolic spatial structure of exoelectrogenic anode biofilms. J. Power Sources 2017, 356, 566-571. [CrossRef]

51. Malvankar, N.S.; Mester, T.; Tuominen, M.T.; Lovely, D.R. Supercapacitors Based on c-Type Cytochromes Using Con-ductive Nanostructured Networks of Living Bacteria. ChemPhysChem 2012, 13, 463-468. [CrossRef]

52. Riedl, S.; Brown, R.K.; Esquivel, D.Y.A.; Wichmann, H.; Huber, K.J.; Bunk, B.; Overmann, J.; Schröder, U. Cultivating Electrochemically Active Biofilms at Continuously Changing Electrode Potentials. ChemElectroChem 2019, 6, 2238-2247. [CrossRef]

53. Massaglia, G.; Margaria, V.; Sacco, A.; Tommasi, T.; Pentassuglia, S.; Ahmed, D.; Mo, R.; Pirri, C.F.; Quaglio, M. In situ continuous current production from marine floating microbial fuel cells. Appl. Energy 2018, 230, 78-85. [CrossRef]

54. Yang, Y.; Yan, L.; Song, J.; Xu, M. Optimizing the electrode surface area of sediment microbial fuel cells. RSC Adv. 2018, 8, 25319-25324. [CrossRef]

55. Ge, Z.; Wu, L.; Zhang, F.; He, Z. Energy extraction from a large-scale microbial fuel cell system treating municipal wastewater. J. Power Sources 2015, 297, 260-264. [CrossRef]

56. Santoro, C.; Ieropoulos, I.; Greenman, J.; Cristiani, P.; Vadas, T.; Mackay, A.; Li, B. Power generation and contaminant removal in single chamber microbial fuel cells (SCMFCs) treating human urine. Int. J. Hydrogen Energy 2013, 38, 11552-11558. [CrossRef]

57. Ieropoulos, I.A.; Stinchcombe, A.; Gajda, I.; Forbes, S.; Merino-Jimenez, I.; Pasternak, G.; Sanchez-Herranz, D.; Greenman, J. Pee power urinal-Microbial fuel cell technology field trials in the context of sanitation. Environ. Sci. Water Res. Technol. 2016, 2, 336-343. [CrossRef] 